\title{
A study on outcome of penetrating keratoplasty in various types of corneal pathologies
}

\author{
Yamini Rawate ${ }^{1, *}$, Nidhi Pandey ${ }^{2}$ \\ ${ }^{\mathbf{1}}$ Assistant Professor, Dept. of Ophthalmology, Government Medical College Rajnandgaon, Chhattisgarh, ${ }^{2}$ Professor, Dept. of \\ Ophthalmology, Pt. J.N.M. Medical College, Chhattisgarh, India \\ *Corresponding Author: \\ Email: dr.yamini7@gmail.com
}

\begin{abstract}
Introduction: Penetrating keratoplasty involves surgical removal of diseased or damaged cornea from the host and replacement with a full thickness donor cornea. The major goals of penetrating keratoplasty are to improve visual acuity, to maintain the integrity of the eye and to treat various infection or neoplastic conditions. Depending on the location of the corneal abnormality, it may be sufficient to replace the anterior corneal layers (anterior lamellar keratoplasty) or the posterior corneal stroma and endothelium (posterior lamellar keratoplasty or descements stripping endothelial keratoplasty or descements stripping endothelial keratoplasty).

Materials and Methods: This study has been done in department of Ophthalmology, Pt. J.N.M. Medical College, Raipur (C.G) from July 2009 to October 2010 and consists of group of patients attending eye OPD and admitted in department of ophthalmology. All patients included in the study were enquired about their history of diminution of vision, previous surgery, duration and any other associated symptoms. The patients underwent a detailed preoperative examination including visual acuity measurement with snellen's chart, retinoscopy and subjective correction and slit lamp biomicroscopy.

Observations: Among 40 patients 23 were male and 17 were female maximum patients were above 40 years of age. Out of 40 cases (100\%), 23 cases (57.5\%) were therapeutic and 17 cases $(42.5 \%)$ were optical purpose. The mean age of the donor cornea was (61-80 years) age group which is used in 65\% (26) cases. Maximum cases (40\%) had corneal ulcer followed by corneal opacity (35\%) and adherent leucoma (17\%). Out of 40 cases in 32 cases of PKP shows complications. Improvement in visual acuity was seen in majority of cases.

Conclusion: In this study we concluded that penetrating keratoplasty is most useful to save vision and structural integrity in case of corneal blindness.
\end{abstract}

Keywords: Corneal pathologies, Penetrating keratoplasty, Visual acuity.

\section{Introduction}

Penetrating keratoplasty involves surgical removal of diseased or damaged cornea from the host and replacement with a full thickness donor cornea. The major goals of penetrating keratoplasty are to improve visual acuity, to maintain the integrity of the eye and to treat various infection or neoplastic conditions. ${ }^{1}$

Modern methods of eye banking, corneal preservation, and surgical techniques with exquisite precision, early recognition and prompt treatment of complications have made corneal grafting the most successful form of organ transplantation. Indications for penetrating keratoplasty have changed drastically over the last 25 years or so. In the mid twentieth century in developed countries, the most common indications for corneal grafting were scars following herpes simplex keratitis, regrafts and keratoconus. Transplants for cataract extraction related bullous keratopathy becoming a fairly common indication. Penetrating keratoplasty is now one of the most successful transplantation with uncomplicated low-risk grafts having a 2 year survival rate of above $90 \%$ and a 10 year success rate of $70-80 \%$ over the past few decades, penetrating keratoplasty has been much more commonly performed compared to lamellar keratoplasty, owing to its remarkable surgical success. ${ }^{2-}$
However, in recent years, lamellar transplantation procedures have started to achieve more prominence, owing to advances in surgical techniques and instrumentation. Depending on the location of the corneal abnormality, it may be sufficient to replace the anterior corneal layers(anterior lamellar keratoplasty) or the posterior corneal stroma and endothelium (posterior lamellar keratoplasty or descements stripping endothelial keratoplasty or descements stripping endothelial keratoplasty) in additions the use of semi automated microkerotomes (automated lamellar therapeutic keratoplasty) has helped to overcome some of the technical difficulties associated with lamellar surgery and to enhance interface smoothness.

Still penetrating keratoplasty is very popular in India because it is of grade advantage in blindness control program. Blinding eye disease are highly prevalent in India (prevalence rate 1.1\%) the prevalence of blindness has been estimated to be 10-40 time higher than in industrial countries and major cause of visual handicap in India is due to high incidence of corneal infection and ulceration. ${ }^{5,6}$ With the above background, the present study was conducted to assess the outcome of penetrating keratoplasty in various types of corneal pathologies." 


\section{Materials and Methods}

This study has been done in department of Ophthalmology, Pt. J.N.M. Medical College, Raipur (C.G) from July 2009 to October 2010 and consists of group of patients attending eye OPD and admitted in department of ophthalmology.

All patients included in the study were enquired about their history of diminution of vision, previous surgery, duration and any other associated symptoms. The patients underwent a detailed preoperative examination including visual acuity measurement with snellen's chart, retinoscopy and subjective correction and slit lamp biomicroscopy.

Patients also were subjected to a detailed examination to rule out any ocular surface disorder or tear film instability with schirmer's test. Intraocular pressure was recorded with schiotz tonometer or noncontact tonometer whichever method was possible. Patients underwent a detailed fundus examination, and patients with hazy media in whom the fundus could not be visualized underwent a posterior segment ultrasonography.

Investigations were done to rule out diabetes and hypertension and patency of lacrimal drainage system. Informed consent was taken from all the patients.

After the initial bio-data and complete history taking patient underwent thorough clinical examination through slit lamp examination, direct and indirect ophthalmoscope and b scan and registered for PKP.

\section{Inclusion Criteria:}

\section{Recruitment of Host Cornea:}

Optical: Bullous keratopathy, keratoconus, corneal degeneration and dystrophy leucomatous corneal opacity.

Tectonic: Stromal thinning descemetocele

Therapeutic: Inflamed corneal tissue

Cosmetic: Corneal scar

\section{Recruitment of Donor Tissue:}

Donor tissue was removed within 6 hours after death. Viable storage periods of the removed corneo-scleral button was one week and 96 hours in M.K. media.

Grafts from donors $<12$ months or $>85$ years was not used.

\section{Exclusion Criteria \\ For Recipient:}

Immunocompromised patients

Psychiatric patients

Medically uncontrolled glaucoma, intraocular tumour.

For Donor Selection:

Death of unknown cause.

Certain infectious disease of the CNS

Jacob-creutzfeld, SSPE, progressive multifocal leucoencephelopathy.

Certain systemic infections AIDS, Septicaemia, Syphilis, viral hepatitis.

Leukemia and disseminated lymphoma.

Intrinsic eye disease, tumours, active inflammation, previous intraocular surgery.

All the procedures were performed as per standard protocol. Data was recorded in MS EXCEL and checked for its completeness and correctness then it was analysed by suitable statistical software and $\mathrm{P}$ value $<0.05$ was considered as a statistically significant.

\section{Observations}

Table 1: Distribution of patients according to age \& sex

\begin{tabular}{|l|c|c|c|c|c|c|c|}
\hline \multirow{2}{*}{ S. No. } & \multirow{2}{*}{ Age in years } & \multicolumn{2}{|c|}{ Male } & \multicolumn{2}{c|}{ Female } & \multicolumn{2}{c|}{ Total } \\
\cline { 3 - 8 } & & No. & $\mathbf{\%}$ & No. & \% & No. & \% \\
\hline 1. & $1-20$ & 2 & $5 \%$ & 2 & $5 \%$ & 4 & $10 \%$ \\
\hline 2. & $21-40$ & 8 & $20 \%$ & 8 & $20 \%$ & 16 & $40 \%$ \\
\hline 3. & $41-60$ & 10 & $25 \%$ & 7 & $17 \%$ & 17 & $42.5 \%$ \\
\hline 4. & 61 and above & 3 & $7.5 \%$ & - & - & 3 & $7.5 \%$ \\
\hline & Total & 23 & $57.5 \%$ & 17 & $42.5 \%$ & 40 & $100 \%$ \\
\hline
\end{tabular}

Among 40 patients 23 were male and 17 were female maximum patients were above 40 years of age. [Table 1]

Table 2: Graft clarity in each age group

\begin{tabular}{|l|c|c|c|c|c|c|c|c|}
\hline \multirow{3}{*}{ Age in years } & \multicolumn{2}{|c|}{ Post operative graft status } \\
\cline { 2 - 9 } & \multicolumn{2}{|c|}{ Total } & \multicolumn{2}{c|}{ Clear } & \multicolumn{2}{c|}{ Haze } & \multicolumn{2}{c|}{ Opaque } \\
\cline { 2 - 9 } & No. & \% & No. & \% & No. & \% & No. & $\%$ \\
\hline 20 & - & - & - & - & - & - & - & - \\
\hline $21-40$ & 5 & $100 \%$ & 3 & $60 \%$ & 2 & $40 \%$ & - & - \\
\hline $41-60$ & 6 & $100 \%$ & 4 & $66.6 \%$ & 2 & $33.3 \%$ & & - \\
\hline $61-80$ & 26 & $100 \%$ & 16 & $61.5 \%$ & 6 & $23.07 \%$ & 4 & $15.88 \%$ \\
\hline $81-85$ & 3 & $100 \%$ & 1 & $33.33 \%$ & 2 & $66.66 \%$ & - & - \\
\hline
\end{tabular}


Graph 1: Type of keretoplasty

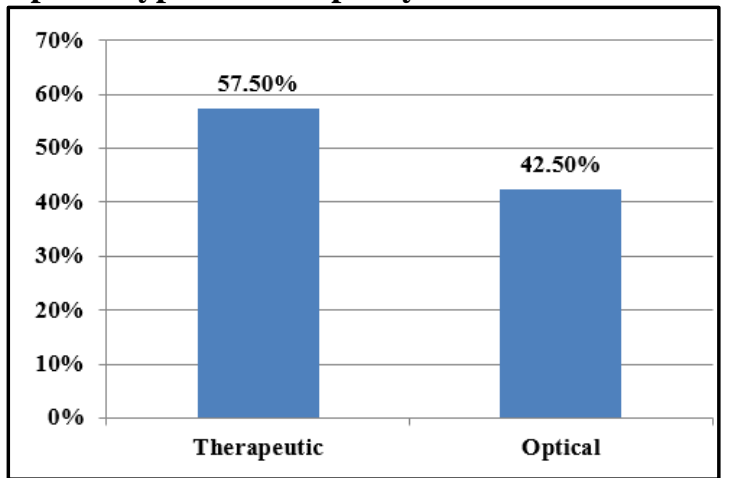

Out of 40 cases $(100 \%), 23$ cases $(57.5 \%)$ were

therapeutic and 17 cases $(42.5 \%)$ were optical purpose.

[Graph 1]
The mean age of the donor cornea was (61-80 years) age group which is used in $65 \%$ (26) cases. Maximum cases were done from donor cornea age group of $61-80$ years i.e., 26 cases. Among 26 cases $16(61.5 \%)$ cases were of clear \& $6(23 \%)$ cases were hazy \& $4(15.38 \%)$ cases were opaque due to primary graft failure. Minimum cases were done from donor cornea age group of $80-85$ years i.e. $3(7.5 \%)$ cases. Most of the cases were clear $(60 \%)$ in postoperative followed by hazy (30\%) \& opaque in $10 \%$ cases. [Table 2]

Table 3: Corneal pathology \& postoperative graft clarity (up to 3 months duration)

\begin{tabular}{|l|c|c|c|c|c|c|c|c|}
\hline \multirow{2}{*}{ Corneal diseases } & \multicolumn{2}{|c|}{ Clear } & \multicolumn{2}{c|}{ Hazy } & \multicolumn{2}{c|}{ Opaque } & \multicolumn{2}{c|}{ Total } \\
\cline { 2 - 10 } & No. & \% & No. & \% & No. & \% & No. & \% \\
\hline Adherent leucoma & 6 & $85.71 \%$ & 1 & $14.28 \%$ & - & - & 7 & $100 \%$ \\
\hline Corneal opacity & 12 & $85.71 \%$ & 2 & $14.28 \%$ & - & - & 14 & $100 \%$ \\
\hline Corneal ulcer & 5 & $31.25 \%$ & 7 & $43.75 \%$ & $4-$ & $25 \%$ & 16 & $100 \%$ \\
\hline Purulent keratitis & 1 & $100 \%$ & - & - & - & - & 1 & $100 \%$ \\
\hline $\begin{array}{l}\text { P'phackic Bullous } \\
\text { Keratopathy }\end{array}$ & 1 & $100 \%$ & - & - & - & - & 1 & $100 \%$ \\
\hline $\begin{array}{l}\text { Aphackic Bullous } \\
\text { keratopathy }\end{array}$ & - & - & 1 & $100 \%$ & - & - & 1 & $100 \%$ \\
\hline & 25 & $62.5 \%$ & 11 & $27.5 \%$ & 4 & $10 \%$ & 40 & 100 \\
\hline
\end{tabular}

Maximum cases (40\%) had corneal ulcer followed by corneal opacity $(35 \%)$ and Adherent Leucoma $(17 \%)$. Out of total 40 cases; in $14(35 \%)$ cases of corneal opacity was the main indication for surgery. Out of these cases of corneal clear graft were obtained in $12(30 \%)$ cases. In $16(40 \%)$ cases of corneal ulcer out of $5(12.5 \%)$ cases were clear and remaining $7(17.5 \%)$ cases were hazy and $4(10 \%)$ cases were opaque. Satisfactory results obtained in p'phackic bullous keratopathy and poor results obtained in corneal ulcer. [Table 3]

Table 4: Corneal pathology and post of complications

\begin{tabular}{|c|c|c|c|c|c|c|c|c|c|c|c|c|}
\hline \multirow[t]{2}{*}{$\begin{array}{c}\text { Post- op. } \\
\text { Complications }\end{array}$} & \multicolumn{2}{|c|}{$\begin{array}{c}\text { Adherent } \\
\text { leucoma }\end{array}$} & \multicolumn{2}{|c|}{$\begin{array}{l}\text { Corneal } \\
\text { Opacity } \\
\end{array}$} & \multicolumn{2}{|c|}{$\begin{array}{c}\text { Corneal } \\
\text { Ulcer }\end{array}$} & \multicolumn{2}{|c|}{$\begin{array}{c}\text { Viral } \\
\text { keratitis }\end{array}$} & \multicolumn{2}{|c|}{ P'BK } & \multicolumn{2}{|c|}{ A'BK } \\
\hline & No. & $\%$ & No. & $\%$ & No. & $\%$ & No. & $\%$ & No. & $\%$ & No. & $\%$ \\
\hline Graft edema & 2 & $20 \%$ & 4 & $40 \%$ & 3 & $30 \%$ & - & - & 1 & $10 \%$ & - & - \\
\hline Epithelial defect & 1 & $16.66 \%$ & 2 & $33.33 \%$ & 3 & $50 \%$ & - & - & - & - & - & - \\
\hline Vascularization & 1 & $50 \%$ & - & - & 1 & $50 \%$ & - & - & - & - & - & - \\
\hline $\begin{array}{l}\text { Graft edema + } \\
\text { Vascular }\end{array}$ & - & - & - & - & 1 & $50 \%$ & - & - & - & - & - & - \\
\hline $\begin{array}{l}\text { Post syn+20 } \\
\text { glaucoma }\end{array}$ & - & - & - & - & - & - & 1 & $100 \%$ & - & - & - & - \\
\hline $\begin{array}{l}\text { Suture } \\
\text { infiltration }\end{array}$ & - & - & 1 & $33.33 \%$ & 2 & $66.66 \%$ & - & - & - & - & - & - \\
\hline Cataract & 1 & $100 \%$ & - & - & - & - & - & - & - & - & - & - \\
\hline $\begin{array}{l}\text { Loose } \\
\text { suture+AC leak }\end{array}$ & - & - & - & - & 1 & $100 \%$ & - & - & - & - & - & - \\
\hline Stromal haze & 1 & $33.33 \%$ & - & - & 1 & $33.33 \%$ & - & - & - & - & 1 & $33.33 \%$ \\
\hline Graft rejection & - & - & 1 & $25 \%$ & 3 & $75 \%$ & - & - & - & - & - & - \\
\hline No complication & - & - & - & - & - & - & - & - & - & - & - & - \\
\hline
\end{tabular}


Out of 40 cases in 32 cases of PKP shows complications. Graft edema present in most of cases found in 10 cases followed by epithelial defect, suture infiltration and stromal haze present $6,3, \& 3$ respectively. Graft rejection seen in 4 cases. [Table 4]

Table 5: Visual acuity at 3 months

\begin{tabular}{|l|c|c|c|c|}
\hline \multirow{2}{*}{} & \multicolumn{2}{|c|}{ Pre operative visual acuity } & \multicolumn{2}{c|}{ Post operative visual acuity } \\
\cline { 2 - 5 } & No. & $\mathbf{\%}$ & No. & \% \\
\hline PL + nt & 12 & $30 \%$ & 9 & $23.5 \%$ \\
\hline HMPLPR & 25 & $62.5 \%$ & 6 & $15.0 \%$ \\
\hline Cf up to 3 ft & 3 & $7.5 \%$ & 4 & $10.0 \%$ \\
\hline Cf up to 5 meter & - & & 13 & $32.0 \%$ \\
\hline $6 / 60$ to 6/36 & - & & 5 & $12.5 \%$ \\
\hline $6 / 24$ to 6/18 & - & & 3 & $7.5 \%$ \\
\hline Total & 40 & $100 \%$ & 40 & $100 \%$ \\
\hline Chi-square - 26.252, d.f.- 5, $\mathrm{p}<0.001$, Significant \\
\hline
\end{tabular}

Improvement in visual acuity was seen in majority of cases. Preoperative visual acuity PL+ was seen in 12 cases $(30 \%)$ while similar post operative visual acuity was seen in only 9 cases $(22.5 \%)$. Postoperative visual acuity up to $3 \mathrm{ft}$ seen in 13 cases (32\%) and up to 6/36 seen in 5 cases $(12.5 \%)$ and up to $6 / 18$ seen in 3 cases $(7.5 \%)$. [Table 5]

\section{Discussion}

In this study incidence of corneal ulcer who was more common in $4^{\text {th }} \& 5^{\text {th }}$ decade of life i.e. $42.5 \%$. This may be due to the fact that with increasing age increases incidence of corneal ulcer with systemic disease (like diabetes, immunocompromised disease).

The indication for PKP in our study correlates well with the Indian as well as western literature. A study done by Dondona L. Ragu K. et al in India common indication for PK were corneal scarring (28.1\%), infectious keratitis (12.2\%), aphakic bullous keratopathy $(11.8 \%)$, psuedophakic bullous keratopathy (10.6\%), corneal dystrophy $(8.4 \%)$, keratoconus $(6 \%)$ and miscellaneous in $(5.9 \%){ }^{7}$ One another study by Ronald E smith et al in western countries where the common indication for PKP were aphakic bullous keratopathy (32\%), psuedophakic bullous keratopathy (28\%), regrafts $(16 \%)$, keratoconus (10\%) and Fuchs endothelial dystrophy $(8 \%) .{ }^{8}$ The difference between Indian \& western literature is accepted because the common corneal pathology in Indian scenario is usually corneal ulcer.

There was a slight preponderance of male patients in this study, this may be due to higher incidence of occupation related corneal pathology \& socioeconomic factors may be the other reason.

In this study out of 40 patients; $23(57.5 \%)$ cases were therapeutic and $17(42.5 \%)$ cases for optical. In this study 16 cases of corneal ulcer was main indication of penetrating keratoplasty. Out of 16 cases of therapeutic penetrating keratoplasty; 5(12.5\%) were clear, $7(17.5 \%)$ were hazy \& $4(10 \%)$ cases were opaque due to graft rejection \& anatomical successes was $97.5 \%$. In our study 1 case was eviscerated due to secondary endophthalmitis.

Dr. Alka Gupta et al (2008) analyzed result of therapeutic penetrating keratoplasty in 70 cases Anatomical success was achieved in all 70 cases(100\%) graft clarity was maintained in $40(57.1 \%)$ eyes, hazy in $30(42.8 \%)$ eyes. Visual outcome $>_{-}=2 / 60$ was obtained in 30 eyes $(42.8 \%)$ and $<-=1 / 60$ was obtained in rest 40 eyes $(57.1 \%){ }^{9}$

In this study, 4 cases $(17.39 \%)$ of therapeutic keratoplasty visual outcome between CF $1 \mathrm{ft}$ to $6 / 24$ were obtained.

In our study rejection rate was common for the age group 61-80 years $(65 \%)$. In CCTS study et al (1994) and Triger et al (2005) observed older age was considered as a risk factor for graft rejection. ${ }^{10-12}$

Bredly et al (2002), it is postulated increasing age causes decrease in acute rejection. ${ }^{13}$

In this study the mean follow up duration was 3 months. Complications encountered in $32(80 \%)$ cases rest remain clear $(20 \%)$. The complications were most commonly encountered in $1^{\text {st }}$ week of postoperative period. Graft edema occurred in 10 (31.25\%) cases, epithelial defect in $6(18.75 \%)$, followed by suture infiltration $(93.6 \%)$, stromal haze in 3 cases $(9.36 \%)$, loose suture $+\mathrm{AC}$ leak in 1 case $(3.12 \%)$ during the follow up period and graft rejection occurred in 4 $(12.48 \%)$ cases.

Out of 4 cases; 1 graft rejection due to secondary endophthalmitis and 2 cases rejected due to secondary infection of graft and 1 due to secondary glaucoma.

In previous study by Sotoru yamagami et al (2009): the risk factor for graft rejection were preoperative endothelial dysfunction (RR-2.3), prior glaucoma (RR2.0), preoperative corneal vascularisation (PR- 4.9) anterior synechiae of iris (RR-1.5), aphakia \& psuedophakia (RR-1.4) and older age (1.3\%). ${ }^{14}$

In this study the preoperative risk factors for graft rejection were in complete or partially treated ulcer in 3 
cases \& preoperative repaired corneal tear with adherent leucoma.

A study of Taban M. Behrens et al (2005) to determine the incidence of acute endophthalmitis following $\mathrm{PK}$ over time, the rate of endophthalmitis was $0.142 \%$ during the $1970 \mathrm{~s}, 0.376 \%$ in the $1980 \mathrm{~s}$, $0.453 \%$ in the 1990 s $\& 0.200 \%$ in the $2000-2003$ period and results indicates drastically decreased incidence of endophthalmitis with PK during last decade due to proper sterilization \& postoperative care. In this study 1 case $(2.5 \%)$ was eviscerated; the difference may be explain by small study size. ${ }^{15}$

Another study of Mansour AL Mahaimeed et al (2002) observed risk of secondary glaucoma after PKP pre-existing glaucoma $(\mathrm{P}<0.001)$ increasing patients age $(\mathrm{P}<0.001)$, previous intraocular surgery $(\mathrm{P}<0.001)$ and the presence of aphakia $(\mathrm{P}=0.002)$ or pseudophakia $(\mathrm{P}<0.001) .{ }^{16}$

\section{Conclusion}

In this study we concluded that penetrating keratoplasty is most useful to save vision and structural integrity in case of corneal blindness.

\section{Acknowledgements}

The authors would like to thank all the faculty and technical staff members of the Department of Opthalmology, Pt. JNM Medical College, Raipur (C.G.) India, for their immense cooperation and support during the entire study.

\section{References}

1. Li Lim et al. Penetrating keratoplasty for keratoconus: visual outcome and success. Ophthalmology. 2000;107(6):1125-1131.

2. S. Gregorey et al. "Corneal ulcer infiltrate associated with soft contact lens use following penetrating keratoplasty" AJO. 1984;3(2):131-134.

3. John C Bear: "Streptococcal endophthalmitis from contamitated donor corneas after keratoplasty" Arch ophthalmol. 1988:106(4):517-520.
4. Y.F Yao et al. Tharapeutic penetrating keratoplasty in severe fungal keratitis using cryopreserved donor corneas. Br J Ophthalmol. 2003 May;87(5):543-547.

5. Density Musch DC: "The effect of allograft rejection after penetrating keratoplasty on central endothelial dystrophy" AMJ opthalmol. 1991;111(6):739-742.

6. Farid karimian "Outcomes of penetrating keratoplasty for macular corneal dystrophy" J ophthalmic vis Res. 2009;4(1)14-18.

7. L. Dondona. Causes of corneal graft failure" Indian Journal of ophthalmology. 1998;46(3):149-152.

8. Ronald E Smith. Changing indication for penetrating keratoplasty (1947 to 1978). Arch ophthalmol.1980;98(7):1126-1229.

9. Alka Gupta et al. Therapeutic penetrating keratoplasty in difficult clinical situations. AIOC 2009 proceeding. 10

10. Price FW Jr, Whitson WE et al. Graft survival in four common groups of patients undergoing penetrating keratoplasty. Ophthalmology. 1991;(3) 322-328.

11. CCTS study (Vail A et al). Conclusions of the corneal transplant follow- up study. Br J Ophthalmol. 1997;81(8):631-636.

12. Triger et al "Corneal graft rejection donor and receiver implication" Jrl Ophthalmol. 2005;28(6): 631-634.

13. Bredly et al: Transplant Immunol 2002;10(2-3):125-132.

14. Sotoru Yamagami et al. Risk factors for graft failure in penetrating keratoplasty. Arch ophthalmology. 1996;74(6):584-588.

15. Toban M Behrens et al. Incidence of acute endophthalmities following penetrating keratoplasty. Arch Ophthalmol. 2005;123(5):605-609.

16. Mansour AL Mahaimeed et al. IJO. 2002;38.222-226.

How to cite this article: Rawate Y, Pandey N. A study on outcome of penetrating keratoplasty in various types of corneal pathologies. Ind $\mathbf{J}$ Clin Exp Ophthalmol. 2018;4(3):358-362. 